\title{
Analysis of control policies and dynamic response of a Q-car 2-DOF semi active system
}

\author{
S.I. Ihsan ${ }^{\mathrm{a}}$, W.F. Faris ${ }^{\mathrm{a}, *}$ and M. Ahmadian ${ }^{\mathrm{b}}$ \\ ${ }^{a}$ Mechanical Engineering Department, College of Engineering, International Islamic University Malaysia, \\ Gombak, Kuala Lumpur, Malaysia \\ ${ }^{\mathrm{b}}$ Mechanical Engineering Department, College of Engineering, Virginia Polytechnic and State University, \\ Blacksburg, VA, USA
}

Received 26 February 2007

Revised 10 July 2007

\begin{abstract}
Several control policies of Q-car 2-DOF semiactive system, namely skyhook, groundhook and hybrid controls are presented. Their ride comfort, suspension displacement and road-holding performances are analyzed and compared with passive system. The analysis covers both transient and steady state responses in time domain and transmissibility response in frequency domain. The results show that the hybrid control policy yields better comfort than a passive suspension, without reducing the road-holding quality or increasing the suspension displacement for typical passenger cars. The hybrid control policy is also shown to be a better compromise between comfort, road-holding and suspension displacement than the skyhook and groundhook control policies.
\end{abstract}

Keywords: Ride comfort, quarter-car model, semiactive system, groundhook, skyhook, hybrid, passive suspension system

\section{Introduction}

Suspension systems are often used to control response of various rigid and flexible multi-body systems $[1,2]$ and the most commonly used suspension systems in vehicular applications, where they are used particularly to control the tire deflection or wheelhop for handling performance and vehicle body deflection and acceleration for passenger ride comfort [3]. Other vehicular applications of such systems include engine, cab and seat suspensions. These so called secondary suspensions increase ride comfort by reducing vibration transmission to the operator compartment [4]. Many works has been conducted to find factors that affect the ride comfort. Demic et al. [5] for example investigated human behavior under random vibrations and shows that human are generally very sensitive to frequency less than $1 \mathrm{~Hz}$.

Since first introduced by Crosby and Karnopp [6,7], semiactive suspension systems continue to gain considerable attention in vehicle applications. This is due to its advantageous characteristics over passive system in overcoming the traditional conflict between vehicle safety and handling, and ride comfort, as well as its significantly less complexity and power requirement than active suspension system [8-10]. Semiactive dampers draw small amounts of energy to operate a valve to adjust the damping level and thus reduce the amount of energy transmitted from the source to the suspended body.

Semiactive dampers can generally be classified based on their control scheme as either on-off skyhook, continuous skyhook, on-off groundhook or continuous groundhook. Skyhook control is known to be able to improve the vehicle body resonance, but at the expense of the tire resonance (wheelhop), while groundhook control provides a better

\footnotetext{
*Corresponding author. E-mail: waleed@iiu.edu.my.
} 
Table 1

States and input description

\begin{tabular}{cll}
\hline Symbol & Description & Units \\
\hline $\mathrm{x}_{1}$ & Suspension deflection & Meters \\
$\mathrm{x}_{2}$ & Sprung mass vertical velocity & Meters/Sec \\
$\mathrm{x}_{3}$ & Tire deflection & Meters \\
$\mathrm{x}_{4}$ & Unsprung mass vertical velocity & Meters/Sec \\
$\mathrm{V}_{\text {in }}$ & Velocity input & Meters/Sec \\
\hline
\end{tabular}

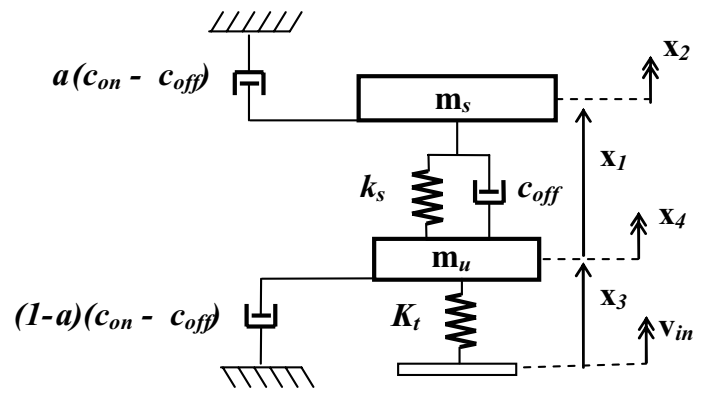

Fig. 1. Quarter-car 2-DOF model.

control of tire resonance, but at the expense of increasing vehicle body resonance. Hybrid control, which combine the effect of both skyhook and groundhook has been introduced and has been shown to provide a compromise between the two while still performing better than the passive system $[4,11]$.

This work intended to look at the performance of each semiactive control policy and compare among themselves and the conventional passive system. The specific performance criteria of interest are the ride comfort, suspension displacement and road-holding responses. A quarter-car model that commonly used in many past suspension studies is considered. This model includes a single suspension system that connects two bodies representing one-quarter of the vehicle body (sprung mass) and one-half of an axle (unsprung mass). The tire stiffness is included as part of the axle.

Three different analyses are presented. The first one is the time-domain transient response analysis, in which the Peak-to-Peak value and settling time are compared. The second is the time-domain steady state response analysis, where the Peak-to-Peak values of pure tone input at resonance frequencies are compared. Finally, frequency responses analyses were conducted and the response curves are compared.

\section{Modeling, derivations and analysis}

A general quarter-car model is used in this analysis and is shown in Fig. 1. From this single model, all semiactive control scheme as well as passive system can be derived. This way of defining the state variables was first introduced by Chalasani [1] and is advantageous in getting the variables of interest in a more direct way. The state variables and input descriptions are provided in Table 1.

The equations of motion derived from the model are shown below:

$$
\begin{aligned}
& \mathrm{k}_{\mathrm{s}} \mathrm{x}_{1}+\mathrm{m}_{\mathrm{s}} \dot{\mathrm{x}}_{2}+\left(\mathrm{c}_{\mathrm{off}}+\alpha\left(\mathrm{c}_{\mathrm{on}}-\mathrm{c}_{\mathrm{off}}\right)\right) \mathrm{x}_{2}-\mathrm{c}_{\mathrm{off}} \mathrm{x}_{4}=0 \\
& -\mathrm{k}_{\mathrm{S}} \mathrm{x}_{1}-\mathrm{c}_{\mathrm{off}} \mathrm{x}_{2}+\mathrm{k}_{\mathrm{t}} \mathrm{x}_{3}+\left(\mathrm{c}_{\mathrm{off}}+(1-\alpha)\left(\mathrm{c}_{\mathrm{on}}-\mathrm{c}_{\mathrm{off}}\right)\right) \mathrm{x}_{4}+\mathrm{m}_{\mathrm{u}} \dot{\mathrm{x}}_{4}=0
\end{aligned}
$$

where the state relation can further be related as:

$$
\begin{aligned}
& \dot{\mathrm{x}}_{1}=\mathrm{x}_{2}-\mathrm{x}_{4} \\
& \dot{\mathrm{x}}_{3}=\mathrm{x}_{4}-\mathrm{v}_{\mathrm{in}}
\end{aligned}
$$


Table 2

Model parameters

\begin{tabular}{cll}
\hline Symbol & Description & Units \\
\hline $\mathrm{m}_{\mathrm{S}}$ & Sprung mass & $240 \mathrm{Kg}$ \\
$\mathrm{m}_{\mathrm{u}}$ & Unsprung mass & $36 \mathrm{Kg}$ \\
$\mathrm{Cs}$ & Suspension damping coefficient & $980 \mathrm{~N} \mathrm{~s} / \mathrm{m}$ \\
$\mathrm{k}_{\mathrm{s}}$ & Suspension stiffness coefficient & $16000 \mathrm{~N} / \mathrm{m}$ \\
$\mathrm{k}_{\mathrm{t}}$ & Tire stiffness coefficient & $160000 \mathrm{~N} / \mathrm{m}$ \\
\hline
\end{tabular}

Table 3

Natural frequencies of each system and control policy

\begin{tabular}{lcc}
\hline System & $\begin{array}{c}\omega_{\mathrm{n} 1}\left(\mathrm{~m}_{\mathrm{s}} \text { natural }\right. \\
\text { frequency }), \mathrm{rad} / \mathrm{s}\end{array}$ & $\begin{array}{c}\omega_{\mathrm{n} 2}\left(\mathrm{~m}_{\mathrm{us}} \text { natural }\right. \\
\text { frequency }), \mathrm{rad} / \mathrm{s}\end{array}$ \\
\hline Passive & 7.8581 & 69.2702 \\
Skyhook & 7.7801 & 69.9642 \\
Groundhook & 7.7813 & 69.9539 \\
Hybrid & 7.7840 & 69.9296 \\
\hline
\end{tabular}

Notice that from this configuration, skyhook and groundhook controls can be obtained by varying the value of $\alpha$. The system becomes a skyhook when $\alpha=1$ and groundhook when $\alpha=0$. The system is said to be in hybrid control when the value of $\alpha$ is between these values. For the purpose of this analysis, hybrid control is defined as when $\alpha=0.5$.

The equations of motion for passive system can be easily obtained from the same figure by letting $\mathrm{c}_{\text {off } 1}=\mathrm{c}_{\mathrm{s} 1}$, $\mathrm{c}_{\mathrm{on} 1}=\mathrm{c}_{\mathrm{s} 1}, \mathrm{c}_{\mathrm{off} 2}=\mathrm{c}_{\mathrm{s} 2}$, and $\mathrm{c}_{\mathrm{on} 2}=\mathrm{c}_{\mathrm{s} 2}$. With these assumptions, the following equations of motion are obtained:

$$
\begin{aligned}
& \mathrm{k}_{\mathrm{s}} \mathrm{x}_{1}+\mathrm{m}_{\mathrm{s}} \dot{\mathrm{x}}_{2}+\mathrm{c}_{\mathrm{s}} \mathrm{x}_{2}-\mathrm{c}_{\mathrm{s}} \mathrm{x}_{4}=0 \\
& -\mathrm{k}_{\mathrm{s}} \mathrm{x}_{1}-\mathrm{c}_{\mathrm{s}} \mathrm{x}_{2}+\mathrm{k}_{\mathrm{t}} \mathrm{x}_{3}+\mathrm{c}_{\mathrm{s}} \mathrm{x}_{4}+\mathrm{m}_{\mathrm{u}} \dot{\mathrm{x}}_{4}=0
\end{aligned}
$$

where the state relation remain the same as Eqs (3) and (4).

The motion variables of interest are suspension deflection $\left(\mathrm{x}_{1}\right)$, sprung mass acceleration $\left(\dot{\mathrm{x}}_{2}\right)$, and tire deflection $\left(\mathrm{x}_{3}\right)$. Unsprung mass acceleration $\left(\dot{\mathrm{x}}_{4}\right)$ is also presented for the sake of comparison, although no significant ride quality can be implied from its result.

The same model parameters are used for every configuration. Their numerical values which are typical for passenger vehicle are summarized in Table 2.

Typical semiactive damping coefficients are chosen using the relationships of $\mathrm{c}_{\mathrm{on}}=2.2 \mathrm{c}_{\mathrm{s}}$ and $\mathrm{c}_{\mathrm{off}}=0.2 \mathrm{c}_{\mathrm{s}}[12]$. These relationships yield to $\left(\mathrm{c}_{\mathrm{on}}-\mathrm{c}_{\mathrm{off}}\right)=2 \mathrm{c}_{\mathrm{s}}$. Using a built-in MATLAB function, the natural frequencies of each system are obtained and shown in Table 3.

These different analyses were conducted to compare the passive to the semiactive control techniques (skyhook, groundhook and hybrid), that are transient and steady state responses in time domain and frequency response. In the transient response analysis, the system is excited with a step input signal. Peak-to-peak value and settling time is noted for each control technique and then compared. In the steady state response analysis, the system is excited with a sinusoidal input with input frequency is set to be equal to the natural frequencies of the system, $\omega_{\mathrm{n} 1}$ and $\omega_{\mathrm{n} 2}$. This is to simulate the worst case scenario in which resonances occur. Finally, transmissibility ratios over frequency span for all variables of interest are presented and the control techniques are compared.

\section{Results and discussion}

\subsection{Transient state response}

The responses for each control technique and passive system are presented in Fig. 2 for sprung mass acceleration, Fig. 3 for unsprung mass acceleration, Fig. 4 for suspension deflection and Fig. 5 for tire deflection. Their Peak-topeak value and settling time are summarized in Figs 6 and 7. 


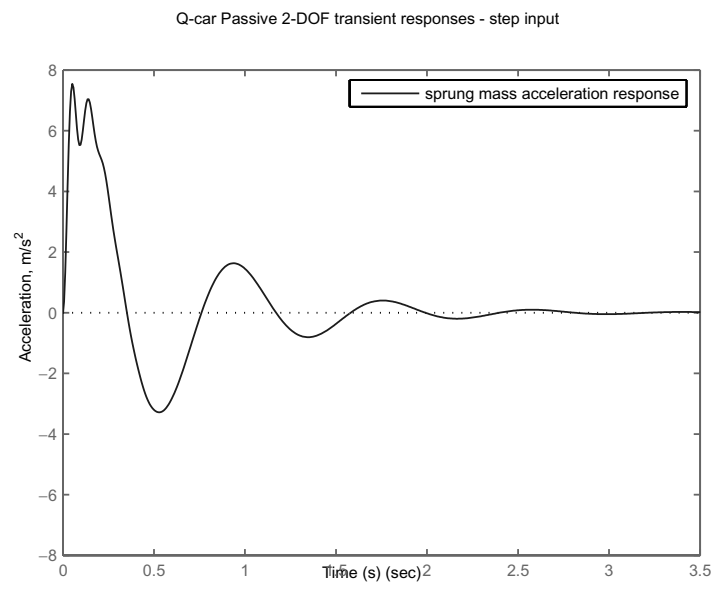

(a) Passive system

Q-car Groundhook 2-DOF transient responses - step input

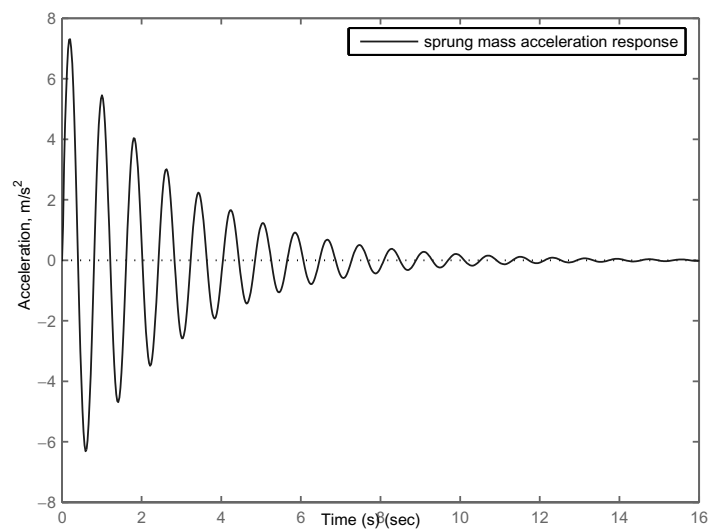

(c) Groundhook control

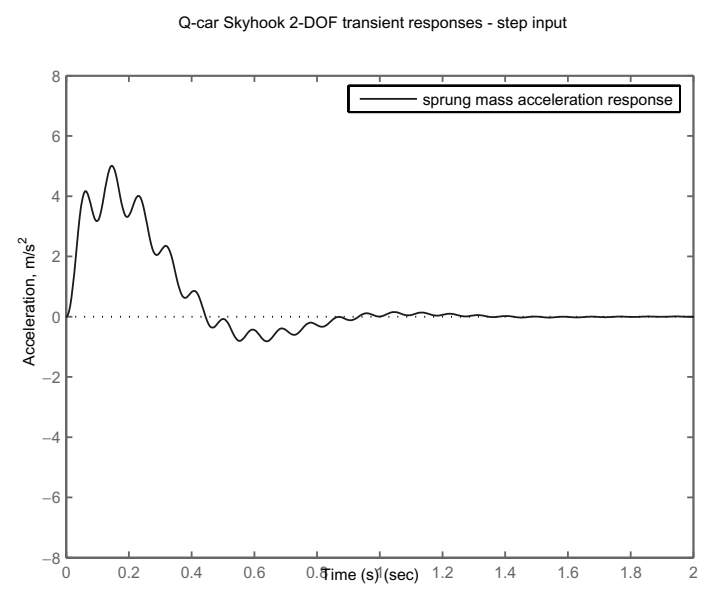

(b) Skyhook control

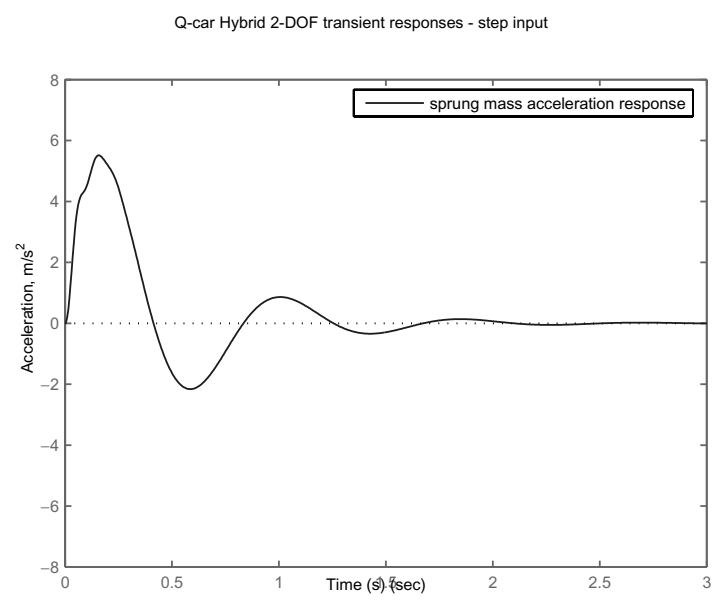

(d) Hybrid control

Fig. 2. Sprung mass acceleration response.

Figure 6 shows that relative to the passive system, skyhook control improves all the performance criteria in the sprung mass response at the expense of the unsprung mass response, where it performs significantly worst than the passive system. Exactly the opposite case is true for the groundhook control. Hybrid control, however, improves all performance criteria in both sprung mass and unsprung mass responses.

Figure 7 shows that relative to the passive system, skyhook control improves all the performance criteria in the suspension deflection response as well as the settling time in the tire deflection response. Its Peak-to-Peak value for the tire deflection however is larger than the passive system. Groundhook control performances are worse than the passive system in all cases. Again, hybrid control improves all performance criteria in both suspension and tire deflection responses.

\subsection{Steady state response}

A summary of the Peak-to-Peak value for each control technique and passive system for both input frequencies, are presented in Fig. 8 for sprung mass and unsprung mass acceleration responses, and Fig. 9 for suspension and tire deflection responses. 


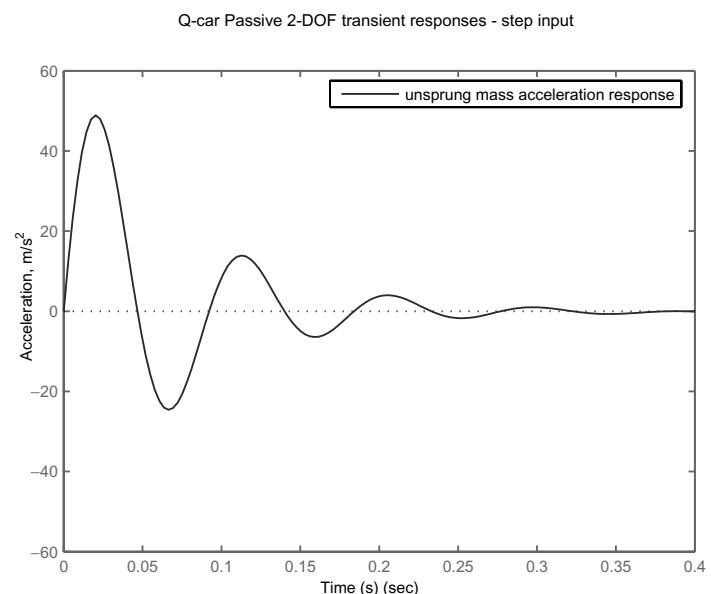

(a) Passive system

Q-car Groundhook 2-DOF transient responses - step input

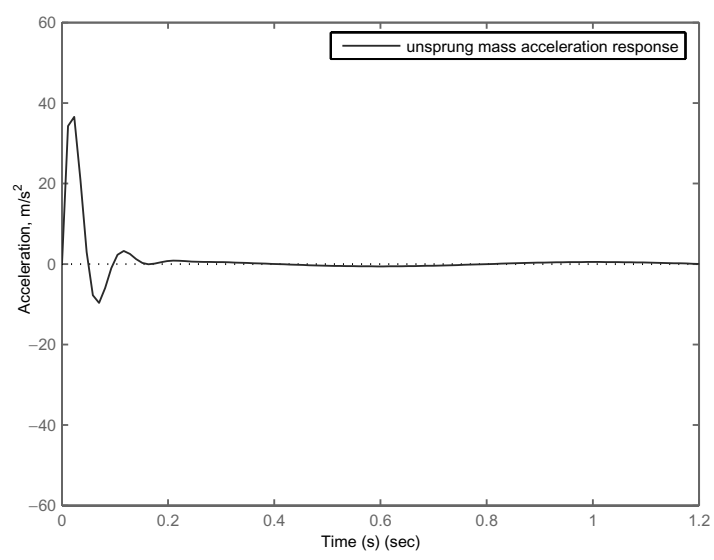

(c) Groundhook control

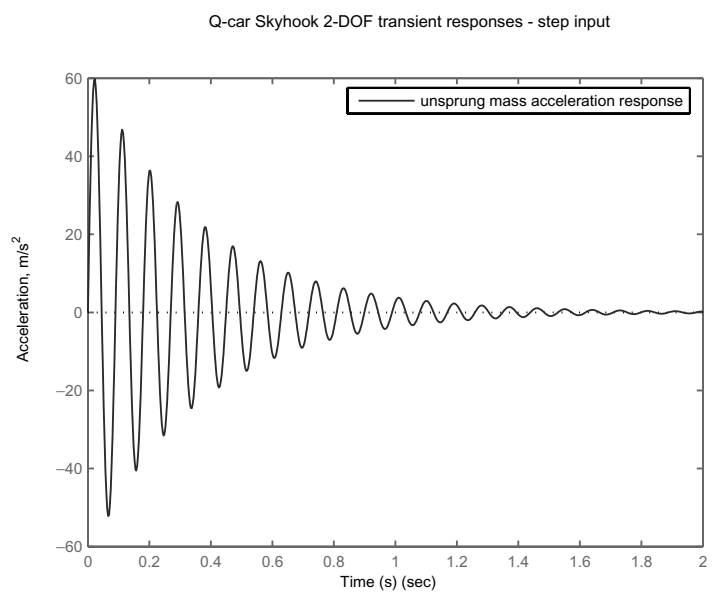

(b) Skyhook control

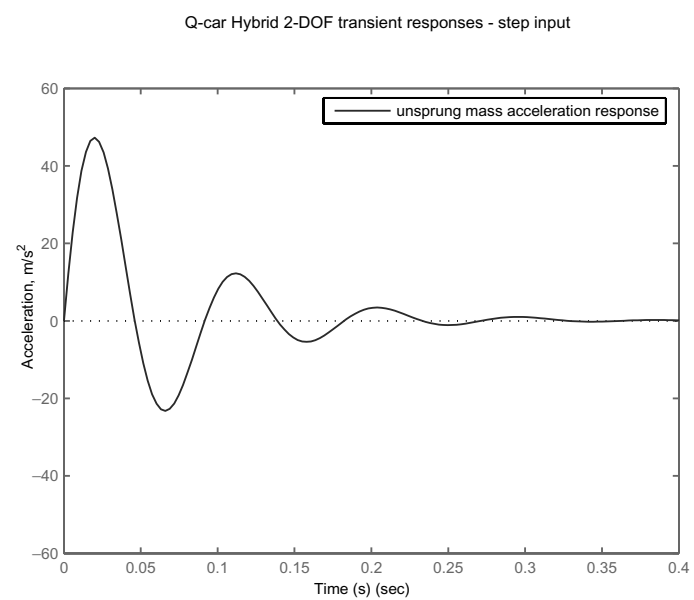

(d) Hybrid control

Fig. 3. Unsprung mass acceleration response.

Figure 8 shows that relative to the passive system, skyhook control performs worse in all cases except for the $\omega_{\text {input }}=\omega_{\mathrm{n} 1}$ case in the sprung mass acceleration response. Groundhook control shows improvement in the $\omega_{\text {input }}=\omega_{\mathrm{n} 2}$ case in both the sprung mass and unsprung mass acceleration response. It performs worse in the $\omega_{\text {input }}=\omega_{\text {n1 }}$ case in both responses. Hybrid control, however performs better in all cases.

Figure 9 shows that relative to the passive system, skyhook control performs better in the $\omega_{\text {input }}=\omega_{\text {n1 }}$ case in both responses but worse in the case of $\omega_{\text {input }}=\omega_{\mathrm{n} 2}$. On the other hand, groundhook control shows improvement in the $\omega_{\text {input }}=\omega_{\mathrm{n} 2}$ case in both the sprung mass and unsprung mass acceleration response. It performs worse in the $\omega_{\text {input }}=\omega_{\text {n1 }}$ case in both responses. Again, hybrid control performs better in all cases.

\subsection{Frequency response}

The transmissibility plot are shown in Fig. 10 for sprung mass and unsprung mass accelerations and Fig. 11 for suspension and tire deflection.

Generally it can be concluded that skyhook control improves the response at the sprung mass natural frequency while increasing the response at the unsprung mass natural frequency. On the other hand, groundhook control 


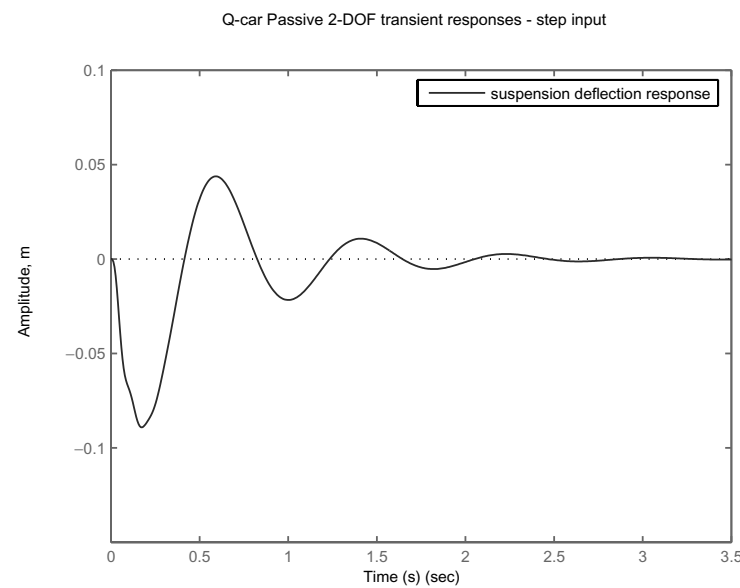

(a) Passive system

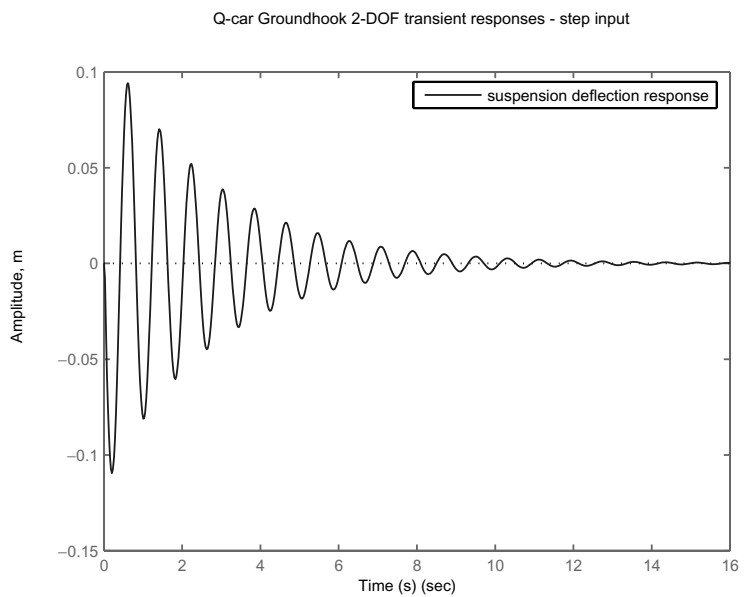

(c) Groundhook control

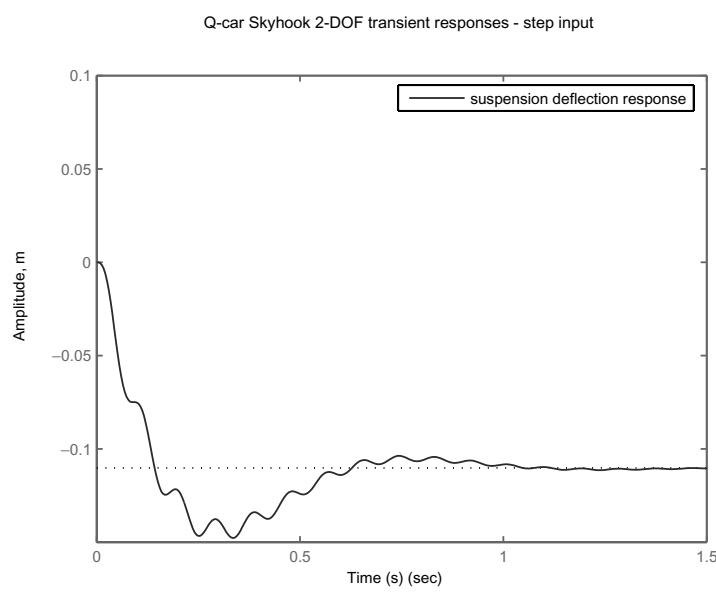

(b) Skyhook control

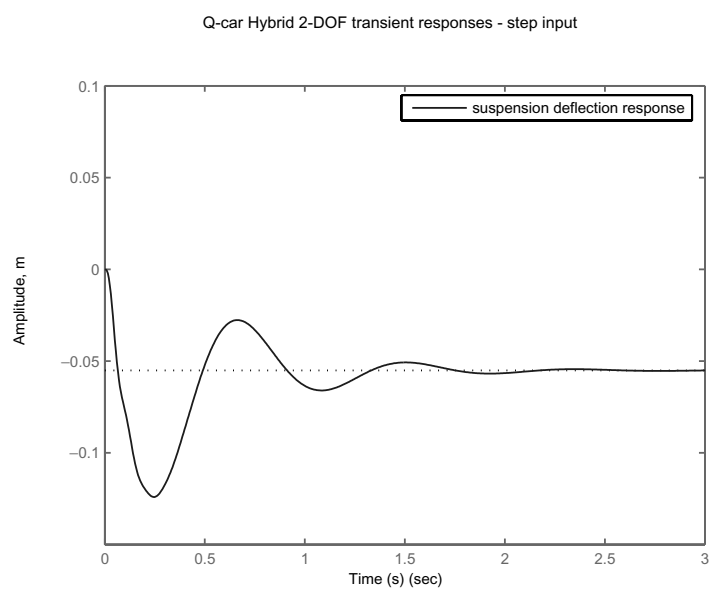

(d) Hybrid control

Fig. 4. Suspension deflection response.

improves the response at the unsprung mass natural frequency while increasing the response at the sprung mass natural frequency. Consistent with the earlier analysis, hybrid control provides sort of compromise response of the semiactive control techniques, while still performs better than the passive system. Significant increase for the skyhook and hybrid controls in the suspension deflection response as well as groundhook control in the tire deflection response are noted.

\section{Conclusion}

Several control policies of Q-car 2-DOF semiactive system, namely skyhook, groundhook and hybrid controls were derived. Their ride comfort, suspension displacement and road-holding performances in time and frequency domains were analyzed and compared with passive system. The results show that the hybrid control policy yields better comfort than a passive suspension, without reducing the road-holding quality or increasing the suspension displacement for typical passenger cars. The hybrid control policy is also shown to be a better compromise between comfort, road-holding and suspension displacement than the skyhook and groundhook control policies. This work is a step in a series of investigative research on different car models and strategies. 


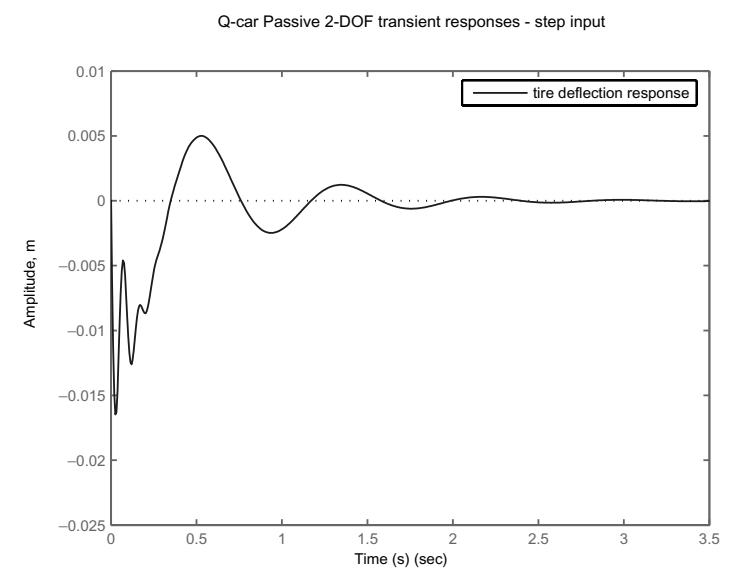

(a) Passive system

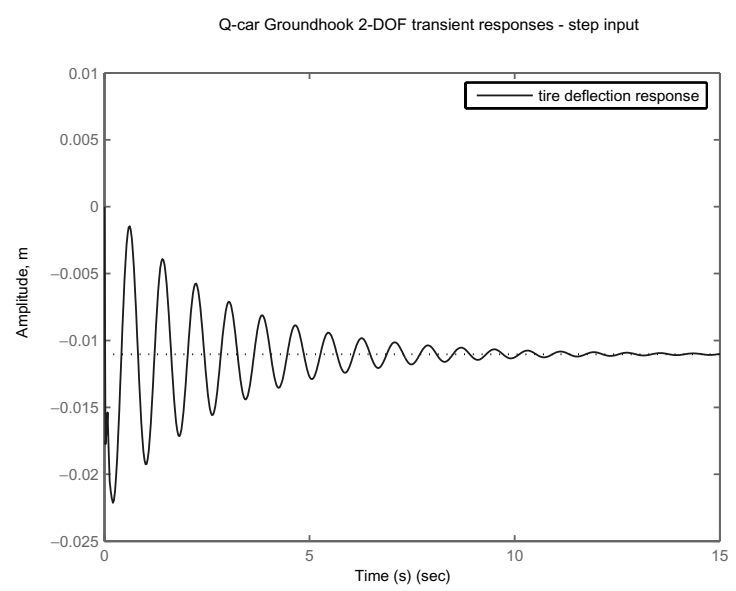

(c) Groundhook control

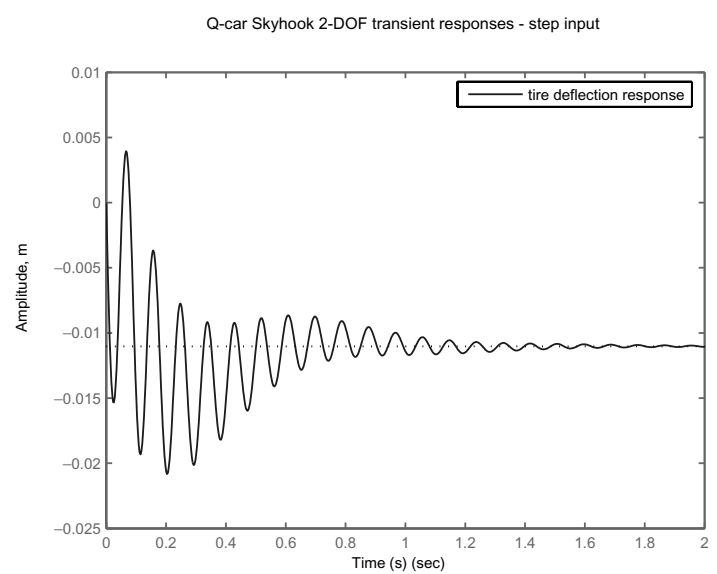

(b) Skyhook control

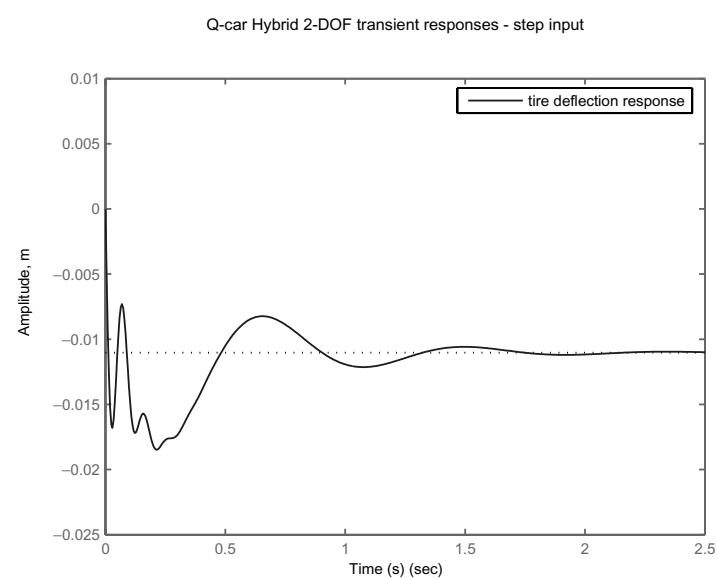

(d) Hybrid control

Fig. 5. Tire deflection response.

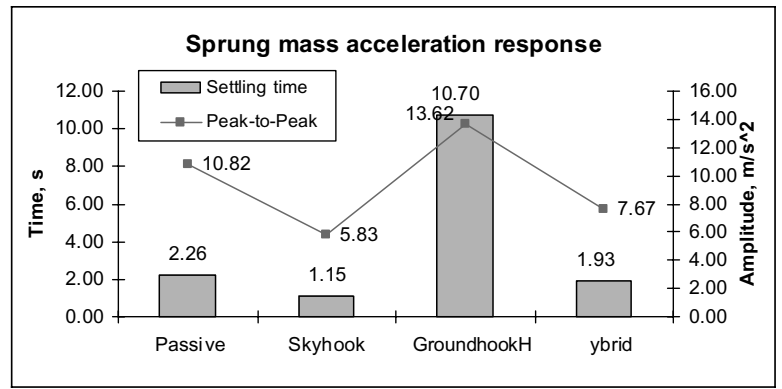

Sprung mass acceleration

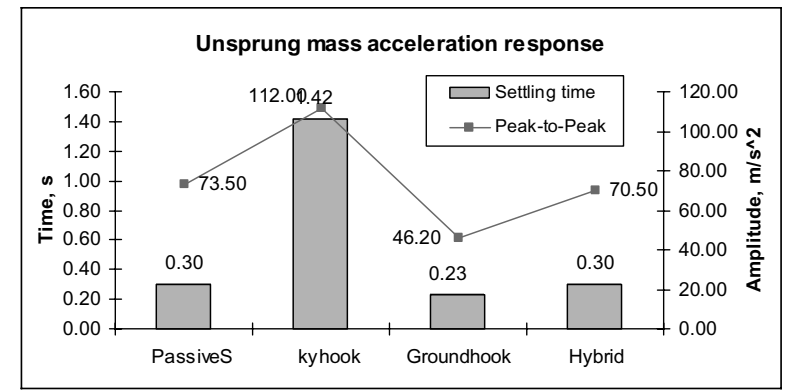

Unsprung mass acceleration

Fig. 6. Summary of results for sprung mass and unsprung mass acceleration response. 


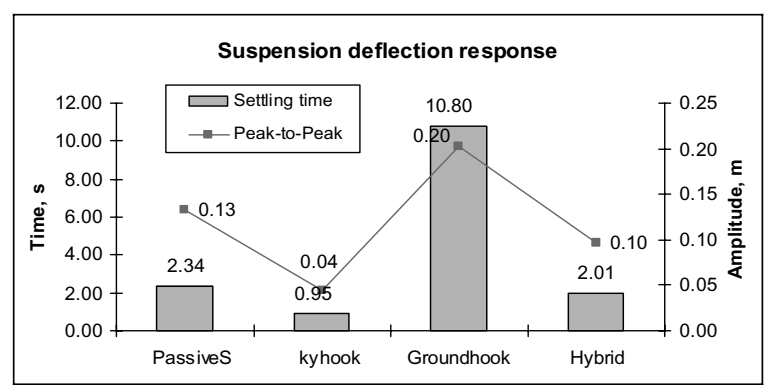

Suspension deflection

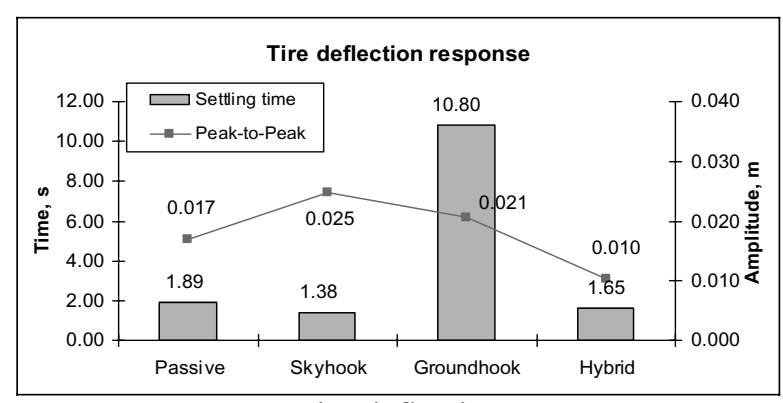

Tire deflection

Fig. 7. Summary of results for suspension and tire deflections response.

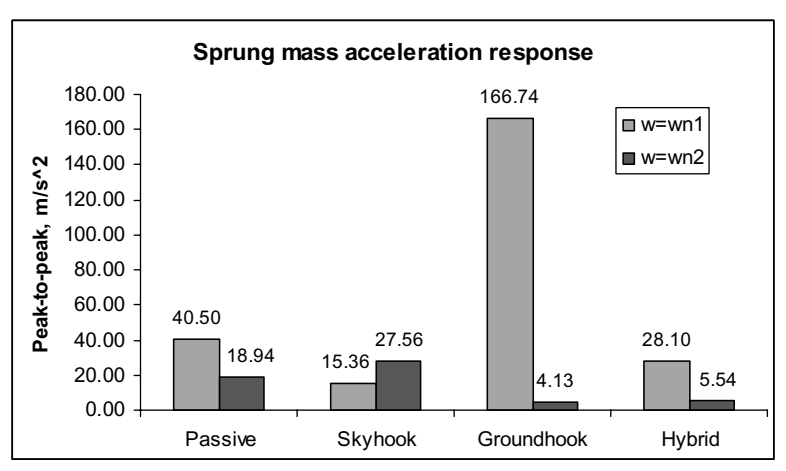

Sprung mass acceleration

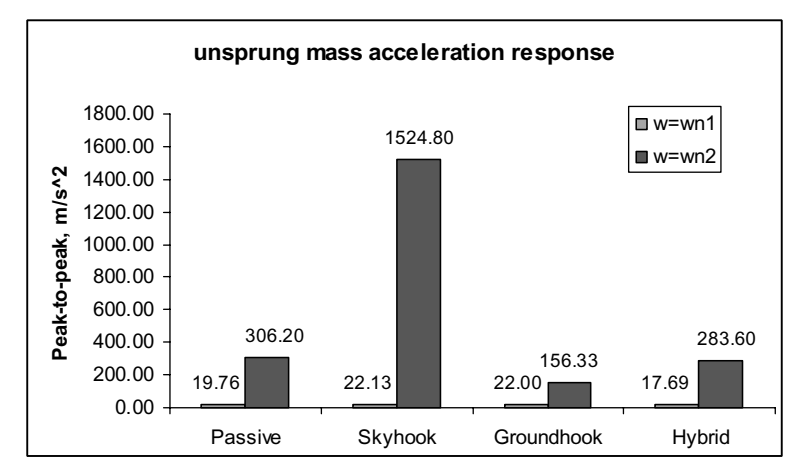

Unsprung mass acceleration

Fig. 8. Peak-to-Peak value for sprung mass and unsprung mass acceleration response.

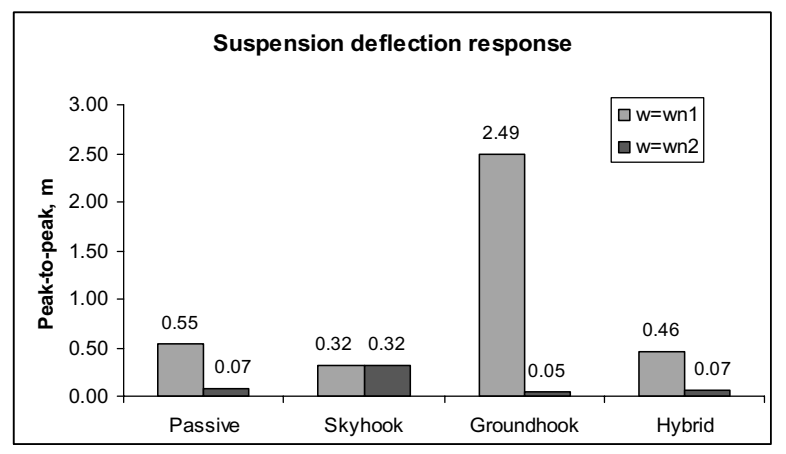

Suspension deflection

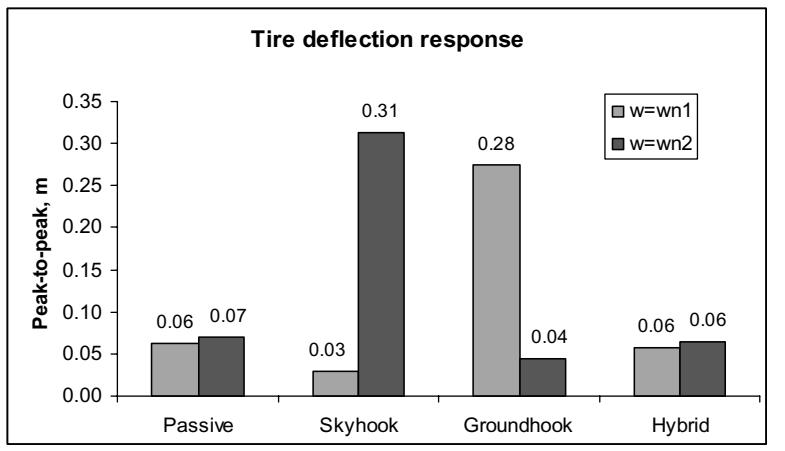

Tire deflection

Fig. 9. Peak-to-Peak value for suspension and tire deflection response. 


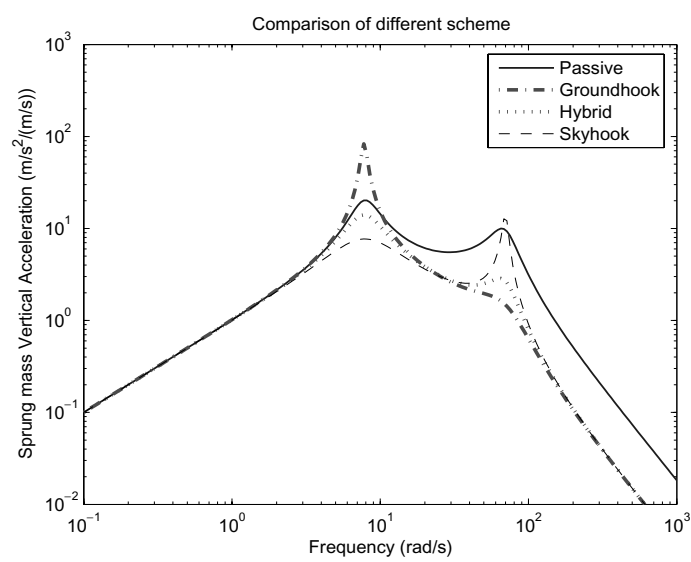

Sprung mass acceleration

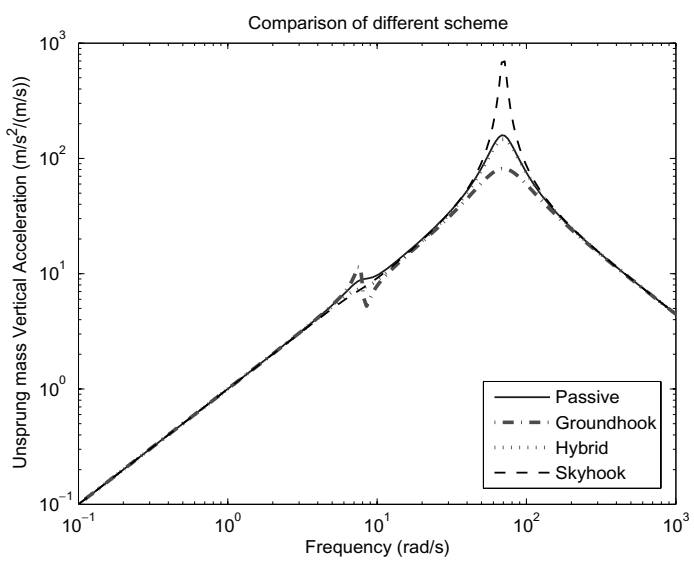

Unsprung mass acceleration

Fig. 10. Sprung mass and unsprung mass acceleration frequency response.

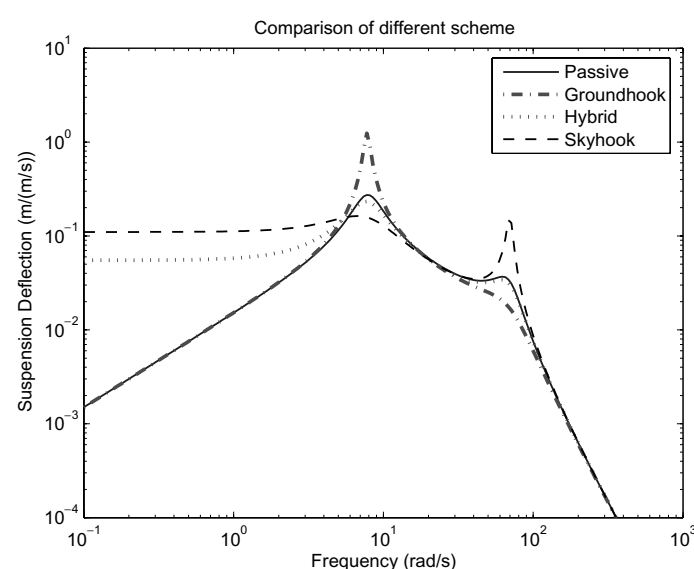

Suspension deflection

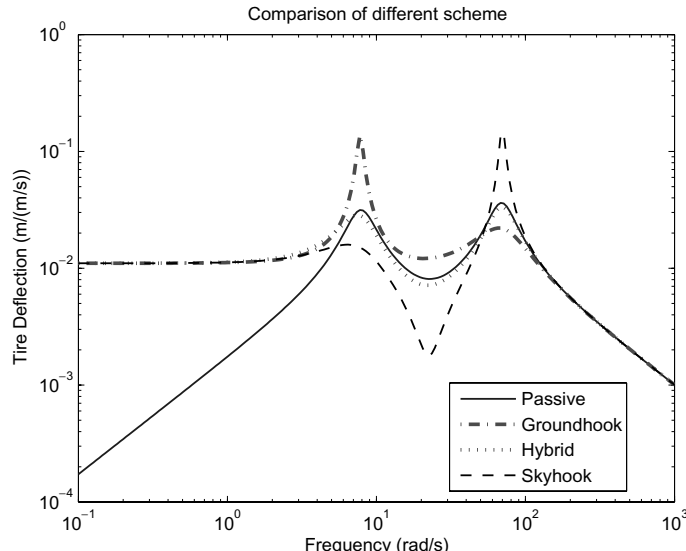

Tire deflection

Fig. 11. Suspension and tire deflection frequency response.

\section{Acknowledgement}

This work is funded by International Islamic University Malaysia (IIUM) Research Grant. A portion of this work was conducted while the first author was at the Center for Vehicle Systems and Safety (CVeSS), Advanced Vehicle Dynamics Laboratory (AVDL), Virginia Tech., Blacksburg, VA as a visiting scholar.

\section{References}

[1] R.M. Chalasani, Ride Performance Potential of Active Suspension Systems - Part I: Simplified Analysis Based on a Quarter-Car Model, ASME Symposium on Simulation and Control of Ground Vehicles and Transportation Systems, AMD-vol. 80, DSC-vol. 2, 1986, $187-204$.

[2] R.M. Chalasani, Ride Performance Potential of Active Suspension Systems - Part II: Comprehensive Analysis Based on a Full-car Model, Proceedings of 1986 ASME Winter Annual Meeting, Los Angeles, CA, December 1986.

[3] M. Ahmadian, Semiactive Control of Multiple Degree of Freedom Systems, Proceedings of 1997 ASME Design Engineering Technical Conferences, Sacramento, CA, September 1997.

[4] M. Ahmadian, A Hybrid Semiactive Control for Secondary Suspension Applications, Proceerings of $6^{\text {th }}$ ASME Symposium on Advanced Automotive Technologies, Dallas, TX, November 1997. 
[5] M. Demic, J. Lukic and Z. Milic, Some aspect of the investigation of random vibration influence on ride comfort, $J$ of Sound and Vibration 253(1) (2002), 109-129.

[6] M.J. Crosby and D.C. Karnopp, "The Active Damper", The Shock and Vibration Bulletin 43, Naval Research Laboratory, Washington, DC, 1973.

[7] D.C. Karnopp and M.J. Crosby, System for Controlling the Transmission of Energy between Spaced Members, US Patent 3,807,678, April 1974.

[8] A.K. Carter, Transient Motion Control of Passive and Semiactive Damping for Vehicle Suspensions, Masters Thesis, Virginia Tech., July 1998.

[9] P. Barak, Passive versus Active and Semi-active Suspension from Theory to Application in North American Industry, SAE Technical Paper 922140, 1992.

[10] J.H. Koo, F.D. Goncalves and M. Ahmadian, Investigation of the response time of magnetorheological fluid dampers, Proceedings of SPIE 2004 Smart Structures and Materials/NDE, San Diego, CA, March 2004.

[11] M. Ahmadian and N. Vahdati, Transient dynamics of semiactive suspensions with hybrid control, Journal of Intelligent Material Systems and Structures 17(2) (February 2006), 145-153.

[12] E.D. Blancard, On the Control Aspects of Semiactive Suspensions for Automobile Applications, Masters Thesis, Virginia Tech. June 2003. 

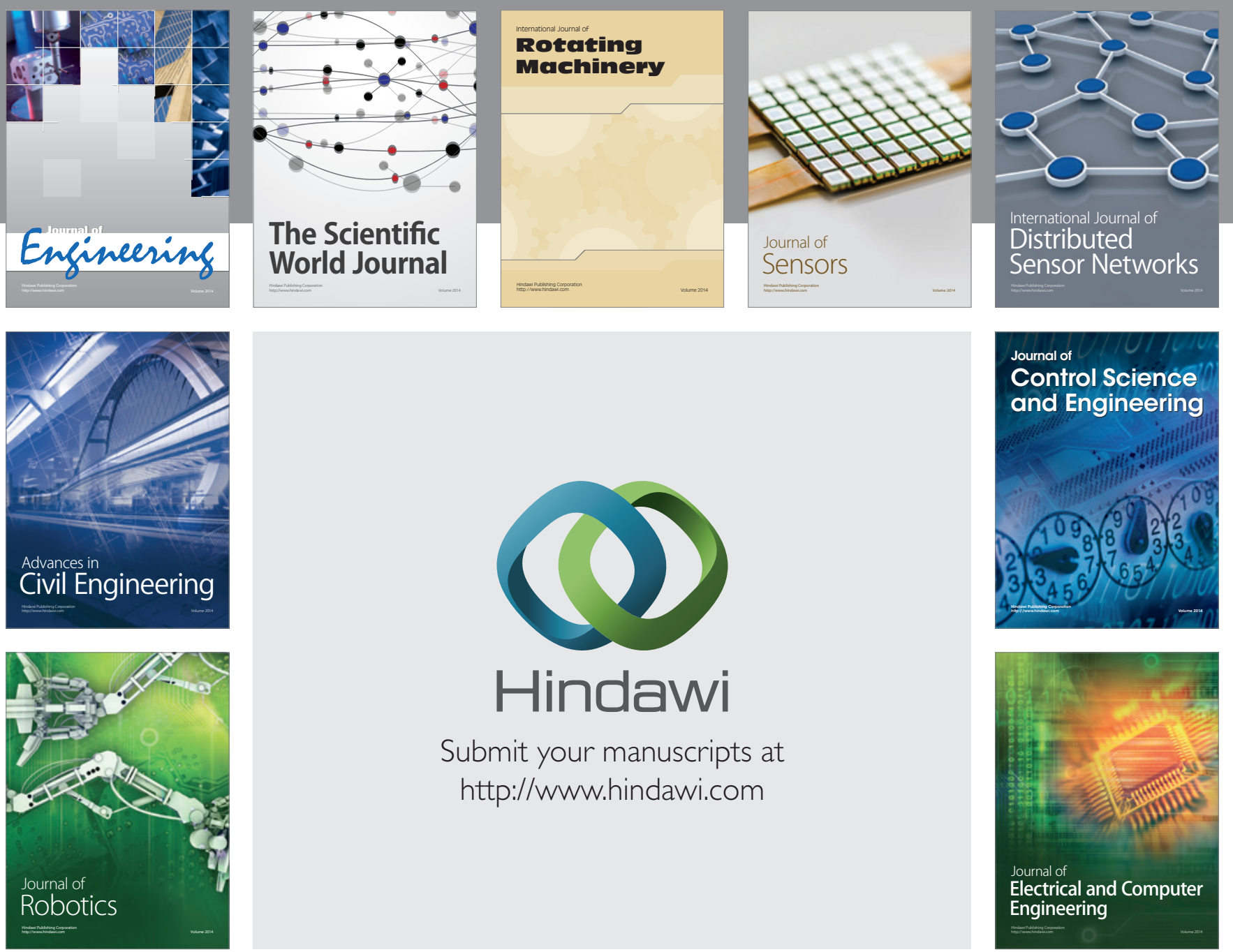

Submit your manuscripts at

http://www.hindawi.com
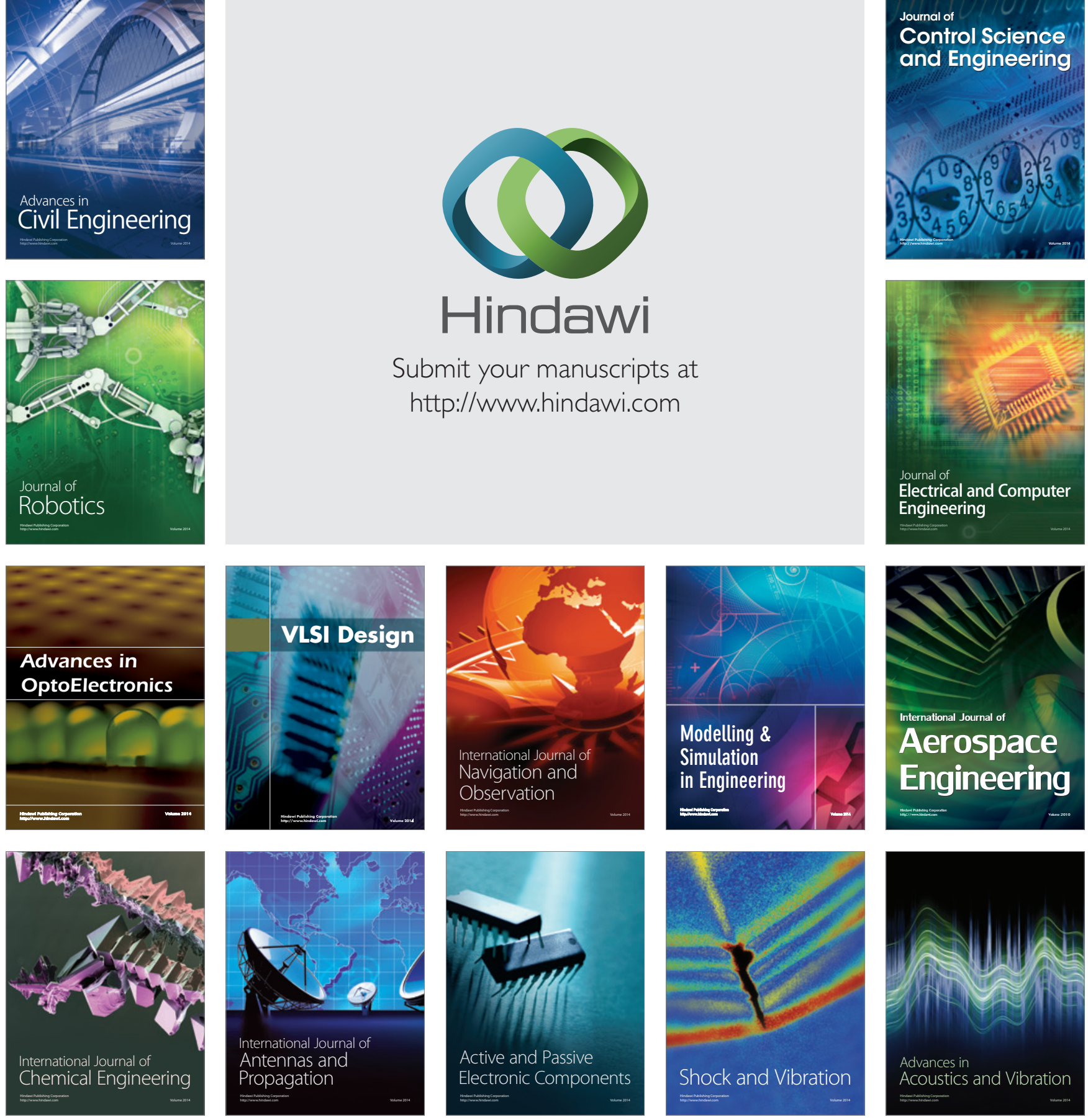